\title{
Los defensores de la humanidad ${ }^{1}$
}

\author{
Antonio-Carlos Pereira Menaut \\ Universidad de Santiago de Compostela (España)
}

Un extraterrestre que llevara los últimos decenios observándonos desde otra galaxia podría tener la sensación de estar presenciando una carrera en la que la técnica ejerce más y más atributos de carácter divino (o considerados hasta ahora como propios de Dios), como seleccionar el sexo o el color de ojos de los hijos, dotar a las personas de más memoria, hacerlas guapas o feas (lo segundo es menos probable), decidir qué vida es digna de ser vivida, y otros más, sin excluir la pretensión de ser inmortales.

Pero el problema -resumidamente- es que, acabe esa carrera donde acabe, al final no va a ser fácil, por no decir imposible, privar a Dios de ninguno de sus atributos, mientras que es fácil que, de rebote, al intentar todo eso, se dañe al hombre -sobre todo al hombre común-, y quizá lo estemos haciendo ya. Uno se pregunta, entonces, quién defiende realmente lo humano.

Antes que nada, preguntémonos: ¿necesariamente va a ser eso así? ¿Puede la asunción de poderes genéricamente divinos por el hombre, redundar en perjuicio del hombre? Por lo pronto, suena anti-intuitivo. Pero en el fondo la respuesta es sencilla: como esos nuevos poderes y atributos, a fortiori se han de ejercitar sobre otros hombres, colocarán a un ser humano sobre otro, y al hacer así, como mínimo se niega la igual dignidad de uno de ellos. ¿Y por qué ha de suceder eso tan rápida y directamente? Porque «hacer de Dios» hoy, a diferencia de otras épocas, no es una discusión de filósofos, en la que nadie de carne y hueso sufre ni padece, ni tampoco es un cambio serio pero lento, cuyos efectos no se puedan imaginar y tal vez tarden siglos (por ejemplo, la opción pro-técnica que en su día tomó Bacon; la opción cartesiana). En nuestros biotecnológicos días, jugar a Dios tiene implicaciones rápidas, que pueden ser incluso físicas para quienes resulten preteridos, descartados, manipulados o cuya vida se juzgue indigna de ser vivida. Más sencillamente: unos hombres tomarán en sus manos

1 [NOTA: Este trabajo reutiliza otros anteriores de este autor: «Who Are the Real Defenders of Humanity?» (Crisis Magazine, 17 de febrero de 2017) y «Guardianes de la Humanidad»; Ius Publicum 41 (2018), 23-33].

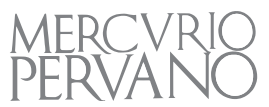


una vida tan humana como las suyas y decidirán protegerla, o tal vez suprimirla; o quizá decidan que si tiene síndrome de Down (como mi nieto Guillermo) no merece ser vivida, o manipularán a otro hombre para 'mejorarlo' o tratarán a un tercero como una res intra commercium, como sucede al poner precios (en la «maternidad subrogada», por ejemplo) y exigir judicialmente el cumplimiento del contrato como se exigiría al fontanero o al dentista. Lo que está sucediendo ahora no es como entronizar, como se hizo en la Revolución francesa, a una Diosa Razón disfrazada, cuya divinidad durará lo que dure la verbena. Tampoco es como decretar en una asamblea política decimonónica que Dios no existe y a continuación irse cada uno a su casa. Es otro mundo; son otros tiempos, más tecnológicos (biotecnológicos, en este caso) y rápidos; tanto para sanar como para dañar, para bien como para mal.

Desde hace tiempo venimos dando por supuesto el «imperativo tecnológico»: que todo avance técnico debe tener luz verde. $\mathrm{Y}$ al mismo tiempo, ya es para nosotros rutina que los últimos avances de la ciencia y la biotecnología -selección de embriones según su calidad, maternidad subrogada, three parenting, producción de ciborgs- se encuentren una y otra vez con barreras y prohibiciones por parte de la religión, la moral, la ética y el Derecho (este último, cada vez menos, y según países). Por lo que se refiere al catolicismo, esto -oponer barreras- viene siendo así más o menos desde la Humanae Vitae de Pablo VI (1968), sin que alteren ese juicio general el hecho de que otros documentos pontificios, más que oponer frenos, celebren cualidades humanas, como la razón en Fides et Ratio y Veritatis Splendor, de Juan Pablo II. No es arriesgado, por tanto, concluir que esa impresión negativa es la dominante en la opinión pública europea y norteamericana, no importando que esas barreras sean, en el fondo, defensas del ser humano, sobre todo, del más débil.

Acostumbrada como está mi generación a creer que en principio todo lo nuevo es mejor, y que todo lo que vaya siendo técnicamente posible será llevado a la práctica tarde o temprano $-\mathrm{y}$ con los actuales medios, más temprano que tarde-, todos esos reales o supuestos frenos al progreso científico-tecnológico tienden a ser genéricamente considerados como (para decirlo benévolamente) carentes de visión, antidemocráticos y, por descontado, contrarios al progreso y al sentido de los tiempos.

Pero, escudriñando críticamente, vemos, tras las apariencias, que tal vez muchas, o algunas, de esas impopulares barreras en realidad no sean contrarias al pueblo, a la gente, especialmente a quienes no somos ricos ni poderosos, y por tanto, aunque fuesen impopulares mediáticamente, no serían antipopulares realmente. No estamos ante la «rebelión de las masas» sino en la de las élites. «Barrera»y «prohibición» no suenan bien, aun habiendo hoy más prohibiciones

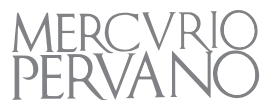


y regulaciones que nunca incluso en nuestras vidas privadas; en cambio, «defensas» sonaría mejor. Pero es un hecho que una barrera puede efectuar, como los diques en Holanda, la función positiva de defender algo valioso, y ahí está la Laudato Si del papa Francisco, defendiendo el Planeta; si bien esto recibe un pase con más facilidad porque suena mejor a los oídos del siglo XXI. Las barreras y prohibiciones (de Dios, del derecho natural, el derecho secular, la moral, la ética, el sentido común) pueden resultar una atadura para quien pide el aborto y para quien se gana la vida practicándolo, o para quien quiere patentar y comercializar embriones, pero protegen al más débil, como el nasciturus con síndrome de Down, y al hacerlo así defienden lo más propiamente humano-indefenso; aquello que, por no tener interés económico ni ir (aparentemente) más allá de lo meramente biológico, quizá no sea defendido por los actuales científicos, con su tendencia a reducirnos a primos hermanos de las algas y amebas; hasta que lo supere la tendencia a reducirnos a algoritmos. Así, las inicialmente antipáticas barreras nos recuerdan que el ser humano es más que biología colocada en un laboratorio para que los biotecnólogos la estudien o manipulen (error de base común a muchas de estas posturas), y nos recuerdan también que con el ser humano no se puede comerciar. Es más: hasta ahora la persona humana siempre estuvo fuera del comercio jurídico. Es muy importante que el Derecho de una comunidad política contenga alguna parte de la que el poder político no pueda disponer libremente -Derecho natural, Derechos históricos, principios-, que por ese mero hecho actuará como una barrera que nos proteja.

Pero déjenme explicar a dónde me gustaría llegar.

II

Es corriente ahora ver el cristianismo, y especialmente la Iglesia católica, como una fortaleza medieval medio en ruinas, resistiéndose como puede ante las sucesivas oleadas de incesantes y proactivas innovaciones de la ciencia y, últimamente, en especial, de la biotecnología. La cosmovisión cristiana, colocada a la defensiva por estos modernos atacantes tan políticamente correctos como implacables, parece sobrevivir, pero perdiendo terreno en cada escaramuza.

Pocas veces he visto últimamente esa sensación expresada de forma tan ingenua y dramática como en el siguiente comentario a un agudo artículo de Anthony Esolen (2018), firmado por un lector llamado Littleeif:

Como persona ya en el final de la vida, la lectura de este ensayo me ha hecho sentir el peso de la carga en que la sabiduría de nuestra época ha venido a convertirse. ¿Cómo puede ser que resulte novedoso leer que la diferencia entre un ser humano y un ordenador es de naturaleza, y no de grado? En esta era, hemos venido finalmente a creer a Nietzsche. Hemos llevado a Marx y Engels desde las raíces industriales hasta la agenda de la postmodernidad. Dejamos que Freud reemplazase el alma y la conciencia. Cedimos la batalla 
del divorcio, y luego del control de natalidad, el aborto y la eutanasia; hasta que el matrimonio, la familia y la propia sexualidad humana ya no tienen un sentido inteligible. Estamos inmersos en esta corriente de pensamiento, empapados por sus racionalizaciones y obligados a sus compromisos. Todo ello nos ha dejado una comprensión plana y pobre de quién y qué es un ser humano. Estamos perfectamente postrados, sometidos, incapaces de explicar o defender nuestro valor. $Y$ esto es intencional, creo.

Sí, la tecnociencia ha golpeado duramente a los cristianos. Y aun se podría añadir los efectos del inhumano capitalismo de especulación, los últimos desarrollos algorítmicos y de la inteligencia artificial, la debilidad de las relaciones interpersonales, la escasez de niños, la erosión de la diferencia entre hombre y mujer, la tendencia a no formar familias, la lucha por la inmortalidad, el hacernos como dioses, que coexiste con un miedo pocas veces visto, y demás.

Pero para emitir un juicio sereno y de conjunto habría que notar que todo eso golpea también al humanismo, a cualquier humanismo. Con estos ataques, Platón, Aristóteles, Cicerón, Séneca o el jurista Papiniano no quedan mucho mejor parados que las viejecitas católicas más tradicionales (si es que queda alguna), y algo no muy distinto puede decirse de la propia Ilustración, que se va a encontrar muy incómoda en tal ambiente. Lo que Littleeif lamenta, también está golpeando al hombre, y a la razón y libertad humanas, y al hombre corriente, que en los hechos, en nuestras vidas reales, no parece muy feliz por haberse quedado sin Dios, sin significados, sin los demás, y, últimamente, sin cosas físicas; solo con legislación positiva, corrección política y datos sobre una base de silicio. Ni siquiera el self, rey de la modernidad, sobrevive; adiós al orgulloso yo y a su autonomía kantiana; lo que defienden los más progresistas ya no es que seamos un montón de células, en el fondo como las de las algas y amebas (como critica Brad Gregory), sino un fajo de algoritmos, al estilo de Yuval Harari. Es inevitable preguntarnos: al final, ¿qué progreso hay para el hombre -incluso para un hombre agnóstico o ateo, siempre que sea antropocéntrico y tenga un mínimo de inocencia y honradez de vida- en pasar de ser el rey de la creación a pasar a la familia de las algas y amebas, o a ser un conjunto de algoritmos, quedando, así, bajo muchos hombres, y tal vez bajo no pocas máquinas? Si no hay self, ¿cómo va a ser libre el self? ¿Qué democracia o qué dignidad humana se construirán sobre algas, amebas, silicio y algoritmos? Ciertamente, ver al hombre como un conjunto de algoritmos es negativo para el alma, y por tanto para toda religiosidad, pero no lo es menos para el orgulloso self occidental, religioso o no (Rubin, 2018); y por cierto que tampoco lo es menos para el cuerpo, pues yo no tengo cuerpo sino que soy cuerpo (y algo más). ¿En esto ha venido a parar el superhombre? La desgarrada retrospección de Littleeif olvida que, como todas las monedas, tiene también otra cara: la democracia, el liberalismo político, el humanismo clásico, la Ilustración, la cultura grecorromana y, en general, el antropocentrismo, el hombre mismo, tampoco salen mejor parados, $\mathrm{y}$, además, algunos de ellos carecen de los resortes morales de los católicos.

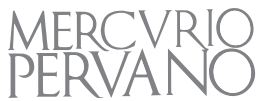


¿Será exagerado concluir que todos esos desarrollos son también negativos para Occidente, como sostienen algunos, generalmente considerados catastrofistas y tradicionalistas? La respuesta es bastante simple y menos ideológica que lo que pueda parecer. Veamos. Seguramente la mayoría estará de acuerdo en que lo que llamamos Occidente coincide, aproximadamente, con el listado de componentes mencionados un poco más arriba: filosofía y política griegas, Derecho romano, la Biblia, el cristianismo, las universidades, la revolución jurídica medieval, el Renacimiento con su humanismo, la Ilustración y las revoluciones liberales. A continuación analícese el impacto de todo lo que Littleeif deplora (para no mencionar lo que podría haber añadido) sobre cada uno de esos componentes, y se concluirá que lo que resulta es un paisaje también hostil para Occidente. Puede que se esté gestando un mundo no cristiano, pero también anti-humano y anti-occidental.

Dicho de otro modo: lo que está siendo bombardeado por la non sancta «alianza del materialismo y la tecnología» (Possenti, 2016) no es solo la Iglesia, ni el cristianismo, sino también, de alguna manera, nosotros los hombres y mujeres comunes y corrientes, nuestra humanidad, y en especial -poca sorpresalos más débiles. Y como muchos de esos ataques no proceden del humanismo, viejo ni nuevo, sino más bien de alguna forma de desconfianza en el hombre de la calle (ni un referéndum se le puede confiar, según los más progresistas, y ahí están el Brexit, Colombia o Cataluña para probarlo), poco nos sorprenderá que el resultado final tienda a deteriorar al hombre y su posición en el cosmos, a fomentar lo no propiamente humano e incluso, quizá, lo inhumano. Reescribir las reglas de lo humano puede ser jugar a Dios, pero también puede ser ir contra el ADN de nuestra realidad, y puede dañar seriamente a la humanidad, así como puede, antidemocráticamente, ponernos a todos en las manos del pequeño número de personas -muy pequeño, en realidad-cuya posición les permite tomar esa clase de decisiones y difundirlas, si es que no imponerlas, por todo el mundo: la 'rebelión de las élites'.

\section{III}

Hagamos ahora una distinción. No toda acción reprobable daña por igual a la humanidad. Robar, posiblemente uno de los más viejos oficios conocidos, va contra las leyes civiles y las naturales y es inmoral, pues res clamant domino suo. Pero no es exactamente inhumano (tal vez sea, incluso, demasiado humano). Algo parecido podríamos decir, mutatis mutandis, de la corrupción económica, la mentira o la calumnia. Incluso la poligamia, el secuestro, el quitar una vida y arriesgar la propia en combate, son todos comportamientos lamentables -especialmente si el secuestrado o muerto soy yo-, pero ninguna de estas desaconsejables actividades es esencialmente anti-humana, ninguna deshumaniza por completo a quien la practique (aunque habría que matizar caso por caso). Volva- 
mos al robo: tras haberme robado mi dinero, soy más pobre que antes, pero mi humanidad y mi dignidad siguen intactas. En cuanto a las guerras, y aunque me profeso pacifista desde que vi el ejército español por dentro en el servicio militar, no se puede negar que exista alguna posibilidad de arriesgar con dignidad la propia vida y las de otros en lo que románticamente se llamó «el campo del honor». Las personas que han hecho guerras así lo testifican; como decía Álvaro d'Ors, es posible el valor sin odio.

Por el contrario, los hijos de tres padres, los vientres de alquiler, la eugenesia o la venta de órganos, colocan intra commercium nuestra misma sustancia humana. Dominus membrorum suorum nemo videtur, dice el Digesto. Tienden, así, a degradar lo humano al status de cosas. Por mucho que uno lo mire, poco de heroico o de digno se alcanza a ver en la acción de encargar niños mejorados o con rasgos preordenados, en seleccionar a las jóvenes donantes de óvulos de modo no muy distinto de como se haría con yeguas de raza, en ofrecer, a las que quieren ser madres sin intervención masculina, semen de varón clasificado por raza y precio, o en manipular personas y producir ciborgs.

No faltará quien alegue que todo eso libera, y quizás retire algunas ataduras a algunos en algún aspecto, pero en todo caso liberará solo a unos pocos: a aquellos que reescribirían el manual de instrucciones del hombre. El grueso de nuestra humanidad, como tal, sería denigrada, y la desigualdad quedaría consagrada; y en grado hasta ahora nunca visto. Y si lo que está siendo manipulado es lo humano, nuestra condición de hombres, la manipulación llegaría a ser no solo inmoralidad (inmoral también es el robo, decíamos) sino también inhumanidad. Irónicamente, ese podría ser el final de las historias como la de Yuval Harari de la superación del homo sapiens por el homo Deus. (Harari no es inconsciente de la desigualdad y de sus desastrosos efectos para los desfavorecidos, y no lo rechaza). Como escriben los abrasivos pero inteligentes Hardt y Negri (2002) al final del capítulo cuarto de Imperio, «ni Dios, ni amo, ni el hombre». ¿Se puede seguir llamando con propiedad a eso humanismo?

\section{IV}

Así que la vieja narrativa católica según la cual ir contra Dios puede ser, al final, ir contra el hombre (p. ej., De Lubac), demostraría ser realista otra vez más.

Con todo, y retomando un punto anterior, yo sugeriría que «jugar a ser Dios» en abstracto, como se pudiera hacer antes, no es tan dramático como deteriorar nuestra humanidad en concreto, pues si Dios existe -y personalmente no alcanzo a ver indicios sólidos contrarios-, nuestros intentos de jugar a Dios o de apropiarnos de atributos suyos, nos afectarán a nosotros y al resto de los hombres, pero no a Él, y no disminuirán un ápice la omnipotencia divina. Ejemplo: hay ahora una moda de escribir «dios» y no «Dios». Aparte de ser mala educación poner en minúscula un nombre propio, al Ser Supremo no lo empe-

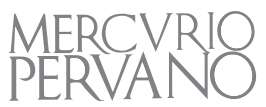


queñecerán en nada, por mucho que empequeñezcan la letra empleada. Es un plan inane, y Dios, que debe de tener sentido del humor, se reirá de ellos. Como curiosidad, me pregunto qué diría un marxista de verdad, de los de antes, acerca de los izquierdistas de «dios» con minúscula pero $\mathrm{XYZ}$ «Banco de $\mathrm{XYZ}$ » con mayúscula.

Desde otro punto de vista -el del constitucionalismo, que es el de este autor-, esa «d», por minúscula que sea, aumentará bien poco el «gobierno del pueblo, por el pueblo y para el pueblo». La sumisión del poder al Derecho tampoco mejorará. Los desmesurados poderes político-económicos de nuestros días acogen sin mayores problemas el postcristianismo, pues no amenaza en nada el inhumano capitalismo de especulación, la concentración del poder o su control sobre nosotros. Los neomarxistas y foucaultianos apostaron por la revolución de los cuerpos («lo personal es lo político», «en esos terrenos se juega la verdadera liberación», etc.), pero fueron unos ingenuos, pues la nueva derecha amoral y postcristiana absorbe todo eso sin pestañear, así que ahora los izquierdistas encuentran que han estado trabajando para el neo-capitalismo, o para las sacrosantas cifras bruselenses de deuda y déficit públicos, e, indirectamente, han trabajado contra las bases sociales de lo que fue la izquierda; no se han alineado con la rebelión de las masas sino con la de las élites. Como escribió el comentarista americano Ross Douthat, si te molesta la derecha cristiana, espera que llegue la post-cristiana. La revolución sexual, más las nuevas tecnologías de la comunicación, más la huida del foro y del ágora, han producido masas de individuos aislados, factores de producción fungibles, sin ataduras familiares y dispuestos a ir a cualquier lugar del mundo, que siempre serán más manejables para el estado y el mercado. Y el mercado, en un mundo postcristiano o post-religioso y carente de sentido común, armonía ni frenos morales, ya ha demostrado que no admite límites.

Expongamos la cuestión de la forma más fría y neutra posible: disputant grammatici, como dirían los antiguos, si Dios existe o no. Disputen si lo desean, pero en caso de que exista, todos los científicos del Planeta opinando unánimemente contra Él, no acortarán su esperanza de vida un minuto (si es que el Eterno tiene «esperanza» de vida). No tenemos capacidad alguna de hacerle verdadero daño (sí de ofenderlo, que es otra cosa). En cambio, cae enteramente dentro de la capacidad de la moderna tecnociencia la posibilidad de dañar seriamente al hombre, así como a la casa del hombre que es la Tierra, y quizá lo estemos haciendo. Ya en los años 50 percibió el agudo Günther Anders, en La Obsolescencia del hombre, el desbordamiento del hombre por la máquina, y eso que en aquel momento la intervención directa en las biologías personales y los balbuceos de la inteligencia artificial no eran mucho más que eso, balbuceos. 
No podemos saber con certeza si Occidente navega en rumbo de colisión con el cristianismo, con la religiosidad humana general, con el simple humanismo e incluso con... Occidente. Indicios, no faltan, pero aún hay que esperar. Con todo, si no de colisión, al menos puede hablarse de alejamiento: es claro que «Occidente» y «cristianismo» ya no coinciden. (Aparte de eso, no sabemos cuánto tiempo podrá seguir hablándose con propiedad de «Occidente» salvo en los libros de historia). Habría que preguntarle a Asia. El common sense va escaseando últimamente -y eso es decisivo para lo que estamos tratando-, incluso en su patria nativa, Inglaterra, pero nadie que conserve un poco negará que, en las últimas décadas, «Los Que Mandan» en el gran buque han mantenido, deliberadamente o no (no lo sé a ciencia cierta), el rumbo de apartarlo de lo que suene a cristiano y, más recientemente, también de lo que suene a personalista, a humanista y a popular. Primero, alejamiento de Dios; después, del hombre, $\mathrm{y}$, últimamente, de las cosas, de la realidad: he ahí la «descosificación» que detectan B. C. Han y otros. Ciertamente, «Los Que Mandan» no son la gente en general sino unos pocos, pero su capacidad de influir en todos nosotros y en nuestras mentalidades y actitudes, ha demostrado ser notable. Idos son los tiempos en que no parecía existir obstáculo serio alguno entre la cristiandad y el mundo moderno, como se decía en el documento final del Concilio Vaticano II (1965). En España, algo semejante se reeditó cuando, al llegar la democracia constitucional, no pocos parecieron creer que había también llegado el momento de que las dos perfectae societates, la Iglesia y el Estado -ahora constitucionalizado y democratizado-, marchasen de la mano sin conflictos inmanejables. En realidad, Ratzinger había columbrado indicios del alejamiento ya en los años sesenta (Sal de la Tierra, Últimas Conversaciones).

Hoy, el panorama político dominante es menos rosado. La Modernidad ha dejado paso a la postmodernidad, la democracia constitucional a la tiranía soft y el panopticon, el gobierno del Derecho, al Derecho usado por el gobierno, el humanismo a una variedad de posthumanismos, transhumanismos y dataísmos. En cuanto al gobierno del pueblo, por el pueblo y para el pueblo, no está ni se le espera, y la palabra «populismo» se ha convertido casi en un insulto (por algún misterio, «democratismo» no lo es).

Si ese nuevo mundo, nueva sociedad y nueva cultura; esa non sancta alianza de tecnocracias transnacionales, «deshumanismos» (Ballesteros, 2016) y materialismos no altera el rumbo, los personalistas en general, los sanos paganos que queden, los que crean en alguna forma de Derecho indisponible para el poder, las distintas confesiones religiosas serias, y en particular el cristianismo, harían mal si, pro bono pacis, por cortesía mal entendida o para no suscitar reacciones adversas en la gran opinión pública europea y norteamericana, dejasen de defender a la humanidad. Sin duda que ello les colocará en una posición incómoda en ese mundo, pero si lo que quieren es seguir cómodos, tendrán que ceder tanto y en tantos temas, que terminarán neutralizados.

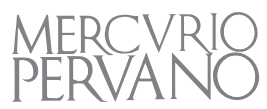


Todos esos grupos citados -los genéricamente «creyentes en el hombre»son los verdaderos defensores de la humanidad. Pero no lo son por blandir una espada flamígera ante «los bárbaros a las puertas». Tampoco lo son solo por rechazar o prohibir (aunque a veces haya que rechazar y prohibir), pues la mera negación no tiene a priori ningún particular mérito. Lo son porque tienen detrás la antropología más adecuada a la realidad del hombre, la cristiana. Podrían ser vulgares y corrientes abuelas católicas atendiendo los deberes escolares de sus nietos, o antihéroes que defiendan lo humano indirecta o hasta inconscientemente (caso de saberlo, algunos serían los primeros sorprendidos), o, a lo peor, incluso alguno con "cara de vinagre». Todo ello puede volver sus mensajes más difíciles de «vender» a la actual audiencia, y en particular a los grandes medios, pero no destruye el fondo que estamos sosteniendo. La «vendibilidad» es muy importante para hacerse entender, pero con el rumbo que lleva el mundo de hoy, cada día será menor, y por ello no puede ser la única vara de medir nuestras proposiciones. Juan Pablo II fue capaz de hablar al corazón de todo hombre con una capacidad de comunicación extraordinaria, pero no todo el mundo lo es; para no mencionar que el hombre de la época de Juan Pablo II (1920-2005), en tan pocos años, ya no es el mismo que el de hoy. (Ejemplo: ¿cuántos defendían en España el matrimonio homosexual en 2005? Muy pocos). El autor de estas líneas, como cristiano, no reconoce culpa alguna por el hecho de que mi mensaje resulte menos inteligible para mis contemporáneos que para los griegos del siglo I antes de Cristo. Si mis contemporáneos me entienden peor que como me entenderían Cicerón y Virgilio, algo habrán hecho mal por comparación con Cicerón y Virgilio.

«El futuro pertenece a los que aceptan la verdad del hombre», dice James Kalb. Sí, y a los que profesan que res sunt, las cosas son como son, la verdad de las cosas. Así que quienes creemos en el hombre -desde los paganos precristianos hasta los variados grupos que cada año marchan por la vida en Washington; pasando por judíos, musulmanes, personas de simple sentido común o filósofos como Habermas- debemos siempre empeñarnos ante todo en razonar con los defensores del posthumanismo, de los cyborgs, del 'dataísmo' y de reconocer la personalidad del pulpo (la cual recalificaría en Galicia como canibalismo masivo el popular polbo á feira, uno de los más sabrosos platos del mundo). A falta de un acuerdo fundamental, hoy cada vez más escaso y muy difícil o imposible de restaurar, sería bueno alcanzar uno procedimental, pero siempre que no estuviera vacío de contenido real, que se tomara en serio por todos y que no fuera una imposición imperialista, como, por ejemplo, el famoso 'Principialismo' bioético de Beauchamp y Childress, que americaniza lo que toca, lo cual es inaceptable por americanófilo que uno sea, como este autor.

Por tanto, no sería realista ignorar que, según pasa el tiempo y avanza la postguerra fría, más difícil resulta localizar un suelo común ya no entre católicos y otros cristianos, católicos y ateos, sino entre creyentes en el hombre y no creyentes 
en el hombre. También hay quien cree que el diálogo entre Occidente (o lo que quede) y las demás civilizaciones es arduo y limitado solo a las materias más obvias. Solo el tiempo lo dirá. Es de suponer que siempre compartiremos, al menos, el logos, y ahí ya encontraríamos una base, pero según avanza el tiempo, ni siquiera eso es seguro, y no solo entre las civilizaciones, sino entre las personas. Cada día oímos más comentarios del tipo de «Me es difícil mantener una conversación, ni siquiera para discrepar». Ello daña la comunicación, con el correspondiente efecto negativo para las relaciones interpersonales. «Diálogo» viene de diá y logos, y el logos lo compartimos todos por ser inherente al ser humano, pero puede volverse difícil con los post-, anti- o trans-humanos. El desacuerdo fundamental no cesa de ensancharse hasta haberse hecho ruidosamente evidente en la política norteamericana y europea de hoy (si bien eso es más consecuencia que causa). Siempre habrá personas particularmente dialogantes, pero cuando el desacuerdo pase ciertas líneas rojas, imposibles de concretar pero reales, va a ser difícil. Ya tenemos experiencias históricas. Los hinchas de fútbol más encarnizadamente rivales puede que lleguen a matarse, pero aunque no lo sepan están de acuerdo en casi todo -a qué jugamos, campo de juego, reglas, árbitro-, menos el resultado del partido. Si discreparan acerca de a qué se juega, el campo, las marcas en el suelo y las reglas, sería imposible celebrar el partido. Cuantas más cosas afecte el desacuerdo, menor posibilidad de dialogar con fruto. El historiador Philippe Nemo ve muy difícil el diálogo de Occidente con otras civilizaciones. No sé hasta qué punto es así, pero con los negadores de lo humano, no va a ser más fácil.

Un viejo dicho inglés reza que para hacer un pacto se necesitan dos, pero para romperlo, basta uno, y algo parecido sucede aquí: yo quiero dialogar, pues todo profesor debe disfrutar discutiendo (y especialmente con quien más se le opone), pero no basta con que quiera uno. Así que, aunque nunca cesemos de ir a buscar algo en común con los posthumanistas, los defensores de los animales o de los algoritmos, quienes creemos en el hombre (y especialmente, pienso, los católicos; pero yo, que no mando ni en mi casa, no tengo potestas alguna para ordenar eso a mis correligionarios) no deberíamos dejar de defender la libre e igual dignidad de todo ser humano, su inteligencia racional y su conciencia moral. Debemos defender todo eso como Chesterton defendía sus convicciones ante Shaw: discutiendo tanto (la discusión es la respiración de la universidad) que acabemos haciéndonos amigos, con la ayuda de unas pintas de cerveza, o el equivalente local.

¿Por qué decimos que especialmente la Iglesia católica? No porque el cristianismo, que es una religión revelada, tenga un monopolio de lo humano (eso sería para ella una contradicción casi in terminis), sino porque en esta parte del mundo -no digo que en todas, ni que haya sido así en todas las épocas- se ha quedado casi como la única o principal fuerza que mantiene el estandarte, por dimisión o abandono de otras fuerzas sociales, culturales o espirituales. Cuando, hacia el año 50, Pablo de Tarso dialogó con los filósofos atenienses en el Areópago, no se presentó como el monopolista de lo humano. Por el contrario, se apoyó en los terrenos humanos comunes a cristianos y paganos, que, aunque

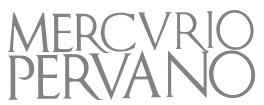


ahora extrañe, eran muchos (sugiero releer el breve y conocido relato), igual que serían muchos si, por hipótesis, el diálogo se hubiera producido con Cicerón. Ellos sí tenían en común el logos, y, lo que es importante, lo usaban.

Como jurista, no ignoro los matices y complejidades del caso, pero, por ejemplo, en la sentencia Paradiso (enero de 2017), los jueces europeos no negaron el real o supuesto derecho de la señora Campanelli a ser madre (aunque como jurista creo que no toda pretensión es un derecho). Indirectamente, al dar un fundamento a la postura que considera que el útero de aquella mujer, así como la criatura que en él vivió, no son commodities comerciables y fungibles, han contribuido a defender la humanidad. Huelga decir que el querer ser madre es muy bueno -la mía lo fue- pero, como casi todo en la vida, no por cualquier procedimiento, ni despreciando los daños colaterales, ni «mercantilizando» o «cosificando» a otros seres humanos iguales a nosotros en dignidad. El principio jurídico básico de que «el fin no justifica los medios» está tan vigente como siempre, y, bajo su aparentemente negativo enunciado, es también una gran defensa para la humanidad.

$* * * * *$

Max Weber, en La ética protestante, dijo que, ausente Dios, el mundo está gobernado por los demonios. No estoy seguro de ello -«no recurras a la maldad humana mientras las cosas se expliquen por la estupidez humana» (Navaja de Hanlon)- y, por la cuenta que me trae, espero que no sea literalmente así. Con que esté gobernado por élites transnacionales no responsables ante nadie, inhumano capitalismo de especulación, falta de sentido común, deshumanismo, tecnocracias globales, biotecnologías descarriladas, políticos necios que «oyen voces en el aire», etc., ya es fastidio suficiente.

\section{Referencias bibliográficas}

Ballesteros, J. (2016). Tipos de deshumanismos: la confusión humano/no humano. En Caronell, C. y L. Flamarique (eds.), De simios, cyborgsy dioses. La naturalización del hombre a debate (pp. 175-194). Madrid: Biblioteca Nueva.

Esolen, A. (28 de junio de 2018). How Is a Man Not Like a Computer? Crisis Magazine.

Negri, T. y Hardt, M. (2002). Imperio. Barcelona: Paidós.

Possenti, V. (2016). La revolución biopolítica: la peligrosa alianza entre materialismo y técnica. Madrid: Rialp.

Rubin, C. (28 de junio de 2018). Algorithmic Man: Yuval Noah Harari's Timid Transhumanism, Public Discourse. 